\title{
Evaluation of the Mechanical Properties of Particleboards Manufactured with Waste of Pinuselliottii Tree Pruning
}

\author{
Sabrina Fernanda Sartório Pole to ${ }^{1}$, Luciano Donize ti Varanda ${ }^{1}$, Maria Fátima do Nascimento ${ }^{1}$, \\ André Luis Chris toforo ${ }^{2, *}$, Francisco Antonio Rocco Lahr ${ }^{1}$ \\ ${ }^{1}$ Department ofStructural Engineering, En gin eering School of São Carlos (EESC/USP), São Carlos, 13566-590, Brazil
${ }^{2}$ Department of Mechanical En gin eering, Fed eral University of São João del-Rei (UFSJ), São João del-Rei, 36307-352, Brazil
}

\begin{abstract}
This work aimed to evaluate the bending strength (MOR) and the bending modulus of elasticity (MOE) of particle boards manufactured with Pinuselliottii and Eucalyptusgrandis species and the addition of waste of Pinuselliottii tree pruning, using a bicomponent polyurethane resin-based castor oil as an adhesive. We prepared nine different experimental conditions, six of the composition of particles of wood (Pinus and Eucalyptus) with pruning residue $(30 \%$, $50 \%$ and $70 \%$ waste) and other three made with $100 \%$ of each one of the three types of particle used, evaluated by the analys is of variance (ANOVA). The panels were prepared by adding $12 \%$ of polyurethane resin on the mass particle with a mo isture content of $11 \%$, using compaction pressure of $4.5 \mathrm{MPa}$ and hot pressing of $90^{\circ} \mathrm{C}$. The results showed that the inclusion of pruning residues reduced significantly the strength and stiffness properties of the panels when compared with the materials manufacture dintegrally with Pinusor Eucalyptus particles. The MOR of the materials in all conditions test ed was less than the $18 \mathrm{MPa}$, limit value set by the Brazilian standard, shown to be necessary to adjust the parameters process used for the achievement of the regulatory requirements.
\end{abstract}

Keywords Particleboards, Polyurethane Resin-based Castor, Waste Tree Pruning

\section{Introduction}

Several researches have been developed in the preparation of particleboards, aiming to verify the feasibility of preparing materials upon certain factors and experimental levels stipulated, and the adhesives of urea-formaldehyde used the most[1].

Widsten et al.[2] studied the influence of high temperature shredding in the physical and mechanical properties of MDF made with hard wood fibers. The authors concluded that the fibers showed better reactivity during bonding by shredding at high temperature, providing progressive breakdown of the lignin polymer contained in the fibers, facilitating the accession process and generally improving the physical and mechanical properties of the panels.

Nemli et al.[3] evaluated the emission of formaldehyde, bending modulus, bending strength, adhesion, thickness swelling and internal adhesion in panels manufactured with mimosa wood particles and with the addition of bark

* Corresponding author:

lchristoforo@yahoo.com.br (André Luis Christoforo)

Published online at http://journal.sapub.org/cmaterials

Copyright (C) 2013 Scientific \& Academic Publishing. All Rights Reserved residues. The panels prepared with the inclusion of the residues of bark investigated reduced the mechanical properties when compared to panels manufactured without waste, significantly reducing the emission of formaldehyde and thickness swelling in the manufactured material.

Jun $\mathrm{Li}$ et a1.[4] evaluated the feasibility of using two exotic species of wood larch (Larixgmelinii and Larix sibirica) as raw material for the manufacture of panels, the variables investigated were bending modulus of elasticity (MOE), modulus of rupture (MOR) and internal adhesion (AI). The results obtained for the three variables indicate the possible use of both species of wood in the manufacture of the panels.

AkgülaandÇamlibelb[5] evaluated the strength and stiffness of particleboards made from Rhododendron wood, foundin abundance in the Black Sea region(Turkey), and $14 \%$ of moisture content and adhesive based on urea formaldehyde. The results indicate the use of Rhododendro $n$ wood to produce the panels of medium density.

Tibor et al.[6] evaluated the properties MOE, MOR and internal adhesion (AI) in wood panel of conifer class, originating from the town of Mohács-UNGARY, not getting satisfactory results only for internal adhesion, justified by the manual mixing of adhesive and urea-formaldehyde wood particles, and other results can be 
achieved by using mechanical mixers.

Saffian et a1.[7] studied the feasibility of production of medium density panels in RRIM 2020 rubber tree clones with four years of age, were evaluated the modulus of elasticity (MOE) and rupture (MOR). The results indicated that it is possible to manufacture the panels with clones of the rubber used.

One aspectto consider because of the industrialization of particle boards is to us eproducts that pollute the environment, mainly through the emission of gases. Accordingly it is necessary to develop new products, such as the proposed study by Bradietal.[8], having considered the influence of mixing vegetable oil into the polyure than ematrix of fiberboard. The analysis shows that it is possible to use mixtures of vegetable oil in the polyure than ematrixratio35:65(by weight)for making panels of wood fibers.

Joseph andBeraldo[9] evaluated the performance of physical and mechanical particle boards with bamboo and polyurethane resin-based castor. The results demonstrated thep otential of engineered materials for industrial use.

Dias et al.[10] evaluated the mechanical properties of plywoodpanels made of polyure thane resin-based castor. The results obtained for the MOE not reached the minimum value of $18 \mathrm{Mpais}$ substantiated by thepoor distribution of adhesive during the panel forming process.

Fiorellieta1.[11] developed particle boards bonded with bag asse and polyurethane resin-based castor, investigating the properties: density, swelling, absorption and modulus of elasticity and bending strength. The results indicated the materialas being manufactured from high density,suitable for industrial use, demonstrating the efficiency of the polyurethane resin castor oil based.

Paes et al.[12] evaluated the effect of the combination of pressure $(2.0 ; 3.0 ; 3.5 \mathrm{MPa})$ and temperature $\left(50 ; 60 ; 90^{\circ} \mathrm{C}\right)$ in panels with particulate of Pinus elliottiiwood waste and polyurethane resin-based castor in response variables: density, swelling and water absorption $(0-2 \mathrm{~h}, 2-24 \mathrm{~h}$, and $0-24 \mathrm{~h}$ ) and elastic modulus of rupture, screw pull-out and internal adhesion, concluding that combinations: $3.0 \mathrm{MPa}$ and $90^{\circ} \mathrm{C}$ and $3.5 \mathrm{MPa}$ and $60^{\circ} \mathrm{C}$ showed the best results, proving to be the hot pressing temperature as the most significant variab le quality (finish) of the panels prepared.

Sartori et al.[13] evaluated the mechanical performance of wood panels and reforestation panels particle

Scrushed can esugar with polyurethane resin-based castoras an alternative to the system of lateral closing the trunk collective management center for beef cattle. The physical and mechanical properties obtained have proved the efficiency of the structural model proposed for use in manage ment center.

According to the Brazilian Association of the Industry of Wood Panels[14], Brazil is one of the most advanced countries in the world in the manufacture of particle boards, medium density, with the largest number of factories of last generation, whose annual production amounts currently $612000 \mathrm{~m}^{3}$, accounting for worldwide production a very low percentage considering the timber potential of the country and the technology installed.

Considering the aspects of the potential production of particle boards from Braziland the need for studies that enable the use of new adhesives as well as the use of tree pruning waste, material unexplored in research involving particle boards, this study aimed to develop and evaluate mechanical properties of materials made from waste tree pruning, allowing to evaluate the potential of compounds developed.

\section{Materials and Methods}

For this work, we used pruning of trees(bark) of Pinuselliottii and wood particles of Eucalyptusgrandis and Pinuselliottii species, being prepared and investigated nine experimental conditions(EC), presented in Table 1.

Table 1. Experimental conditions investigated

\begin{tabular}{lc}
\hline CE & Materials \\
\hline C1 & $100 \%$ Eucalyptus grandis \\
C2 & 30\% Pinus elliottii (bark) and $70 \%$ de Eucalyptus grandis \\
C3 & $50 \%$ Pinus elliottii (bark) and $50 \%$ de Eucalyptus grandis \\
C4 & $70 \%$ Pinus elliottii (bark) and $30 \%$ de Eucalyptus grandis \\
C5 & $100 \%$ Pinus elliottii \\
C6 & $30 \%$ Pinus elliottii (bark) and $70 \%$ de Pinus elliottii \\
C7 & $50 \%$ Pinus elliottii (bark) and $50 \%$ de Pinus elliottii \\
C8 & $70 \%$ Pinus elliottii (bark) and $30 \%$ de Pinus elliottii \\
C9 & $100 \%$ ofPinus barkresidue \\
\hline
\end{tabular}

The bicomponent polyurethane resin (PU) derived fromcastor (adhesive) is employed as the compounds manufactured, with low formaldehyde emissionand no extender having $66 \%$ solids, $\mathrm{pH}$ of 8 to 9 and an average bulk density of $1.29 \mathrm{~g} / \mathrm{cm}^{3}$. For the curing process it is necessary touse acatalyst based on commercial sodiumchloride, with solids content of $20 \%$ at a dosage of $2.5 \%$ solids as catalyst for the solids content of the PU, classified as non-toxic [15].

After separate sheets of bark of Pinuselliottii wood, these along with the two wood species were taken into mill to bechopped. After this process, the particles were screened on sieves with mesh of $2.8 \mathrm{~mm}$, dried to a mo isture content of $11 \%$ and subsequently mixed with the polyurethane resin. At this stage, the materials still remain without adhesion with a flour-like appearance. These are placed in a mould(Figure 1a) followed by application of apre-press toob tain cohesive(Figure 1b), and subsequently placed in a hydraulic press(Fig. 1c) and pressing temperature of $90^{\circ} \mathrm{C}$. The compounds of the pressing process consisted in the use of a pressure of $4.5 \mathrm{Mpa}$ for 3 minutes, followed by pressure relief of the pressfor a period of 30 seconds and subsequent employment pressure of $4.5 \mathrm{Mpa}$ for 7 minutes, for a total time of 10 minutes and 30 seconds with pressing for release of gases. This procedure was used for fabrication of all the panels and it was noted that there were no formation of blisters and ruptures in the material. 
For the feasibility of production of the panels from the inputs mentioned, mechanical tests were performed based on standard ABNTNBR14810[16] (parts 2 and 3),being obtained mechanical properties: bending modulus of elasticity(MOE) and bending strength modulus (MOR).

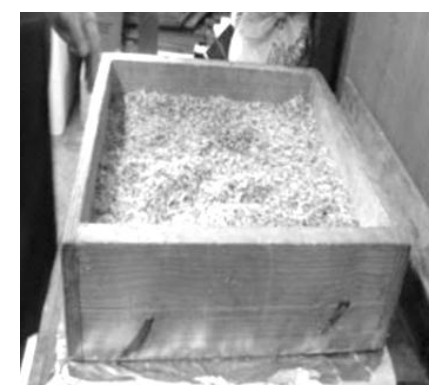

(a)

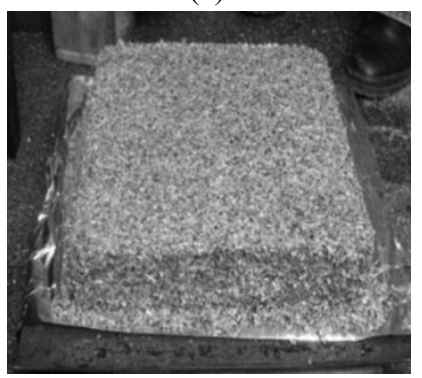

(b)

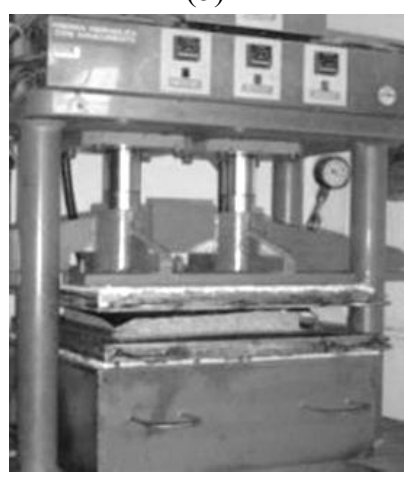

(c)

Figure 1. Forming mattress (a), Mattress particles (b) and hydraulic press (c)

Five particle panels were manufactured for each one of the nine experimental conditions investigated (45 panels), with dimensions $400 \times 400 \times 10 \mathrm{~mm}$, each consisting of $1500 \mathrm{~g}$ of partic les with $180 \mathrm{~g}$ of adhesive, a mounting to $12 \%$ of the mass of particles[10]. After 72hours, the panels wer squared in dimensions $350 \times 350 \times 10 \mathrm{~mm}$. Each one panel were extracted seven specimens for bending tests, with dimension $50 \times 250 \times 10 \mathrm{~mm}$, leading to 315 trials.

The analysis of variance(ANOVA) were used to evaluate the efficiency in the mechanical properties of compounds produced with the inclusion of the pruningresidues. For this purpose,three independent groups were evaluated, relating to the materials of the conditions $\mathrm{C} 1$ to $\mathrm{C} 4$ (Group 1), $\mathrm{C} 5$ to $\mathrm{C} 8$ (Group 2) and $\mathrm{C} 1, \mathrm{C} 5$ andC9 (Group 3).

\section{Results and Discussions}

Table 2 shows the mean value $\left(X_{m}\right)$, coefficient of variation $(\mathrm{CV})$ and $\mathrm{P}$-value of Anderson-Darling normality test referring to the 35 specimens investigated by experimental condition.

Table 2. Results of the mechanical properties

\begin{tabular}{cccc}
\hline CE & \multicolumn{3}{c}{ MOE(MPa) } \\
& $\mathbf{X}_{\mathbf{m}}$ & $\mathbf{C V}(\mathbf{\%})$ & P-value \\
\hline C1 & 1304 & 12 & 0,729 \\
C2 & 1332 & 9 & 0,116 \\
C3 & 1306 & 15 & 0,817 \\
C4 & 1363 & 13 & 0,676 \\
C5 & 1482 & 16 & 0,133 \\
C6 & 1139 & 21 & 0,209 \\
C7 & 1314 & 19 & 0,321 \\
C8 & 1524 & 17 & 0,503 \\
C9 & 891 & 17 & 0,617 \\
\hline \multirow{3}{*}{ CE } & $\mathbf{X}_{\mathbf{m}}$ & MOR(MPa) \\
& $\mathbf{C V}(\mathbf{\%})$ & $\mathbf{P}-\mathbf{v a l u e}$ \\
\hline C1 & 12,91 & 12 & 0,527 \\
C2 & 12,44 & 11 & 0,216 \\
C3 & 11,64 & 11 & 0,983 \\
C4 & 12,24 & 13 & 0,434 \\
C5 & 16,41 & 14 & 0,389 \\
C6 & 9,28 & 20 & 0,873 \\
C7 & 11,35 & 19 & 0,671 \\
C8 & 14,70 & 18 & 0,159 \\
C9 & 7,49 & 19 & 0,180 \\
\hline
\end{tabular}

The coefficients of variation were obtained in accordance with those presented in the work of Fiorellieta1.[11], which gives consistency to there liability of the production process of the panels developed.

The Brazilian standard ABNTNBR14810[16]requires MOR minimum of $18 \mathrm{Mpa}$ for thickness between $8 \mathrm{~mm}$ and $13 \mathrm{~mm}$, but it is not indicating minimum value of MOE instatic bending. The results presented in Table 2 show that materials prepared were unable to reach the threshold value, the largest being obtained from materials manufactured C5 condition, $18.33 \%$ below the reference value.

For analysis of variance (ANOVA) assumptions are made that both samples are extracted from independent populations, which can be described by a normal distribution[17]. The distributions are considered normal when the P-value of the response exceeds 0.05[17].

Table 3 presents the results of the ANOVA for the mean response variables investigated, lying under scores the P-values less than or equal to $0.05(5 \%)$, were considered significantat a confidence level of $95 \%[17]$.

Table 3. P-values of the main fact ors

\begin{tabular}{lll}
\hline \multirow{2}{*}{ Groups } & \multicolumn{2}{c}{ P-value } \\
& MOR & MOE \\
\hline Group1 & $\underline{0,005}$ & 0,415 \\
Group2 & $\underline{0,000}$ & $\underline{0,000}$ \\
Group3 & $\underline{0,000}$ & $\underline{0,000}$ \\
\hline
\end{tabular}

From Table3, Group1 except for the response bending modulus, all other groups showed significant in the mechanical properties MOE and MOR, indicating that the 
inclusion of particles from the waste pruning affected the strength and stiffness properties of the particle boards manufactured.

Figures 2, 3 and 4 shows the main effect plots of experimental conditions by group on the mechanical properties investigated.

Group 1, the inclusion of mass fractions of $30 \%$ and $50 \%$ bark residues when compared to those of the compounds made with $100 \%$ of wood particles of Eucalyptus grandis gave reductions of $3.87 \%$ and $6.21 \%$ respectively in MOR, an increase of $5.15 \%$ from $50 \%$ to $70 \%$ of the fraction particles of bark.

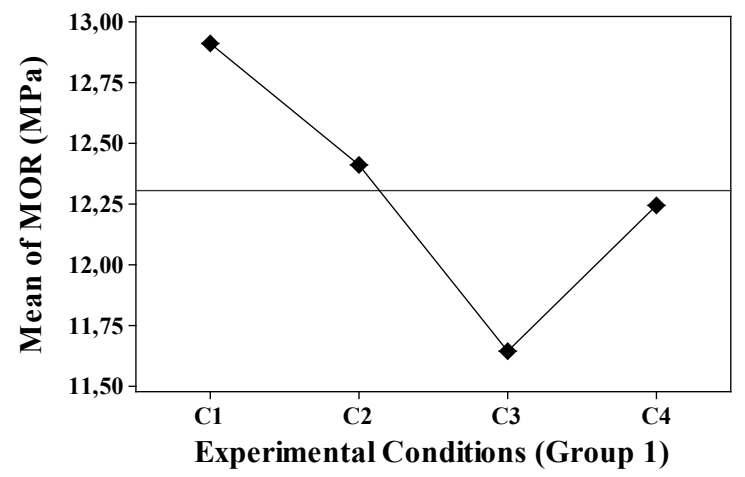

Figure 2. Main effects plot of the experimental condition (Group 1) on MOR

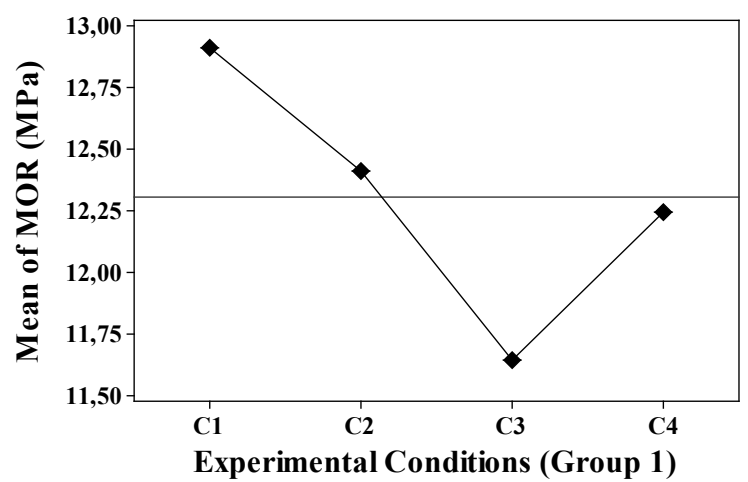

Figure 3. Main effects plot of the experimental condition (Group 1) on MOR

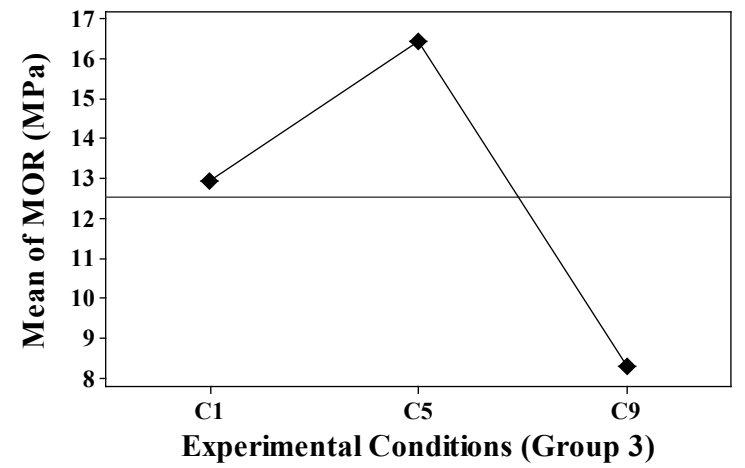

(a)

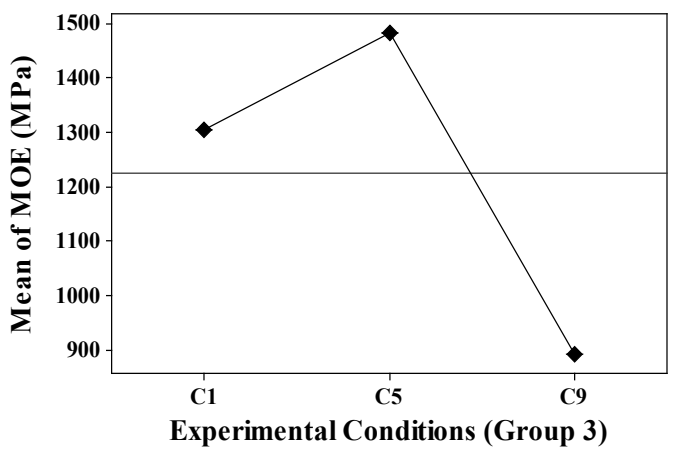

(b)

Figure 4. Main effects plot of the experimental conditions (Group 3) on MOR (a) and MOE (b)

Group2, the progressive inclusion of residues of bark in the compounds gave reductions in the mechanical properties in all compositions when compared with the results of the materials made with $100 \%$ of Pinuselliottii wood particles, and the results obtained under the C8 condition presenting MOR $43.44 \%$ less than the compounds produced in reference condition. The inclusion of $30 \%$ of particles of bark showed $2.81 \%$ increase in bending modulusin the compounds when compared to the results from reference condition(C5),andsuccessive reductions of $11.36 \%$ and $23.77 \%$ with increases of $50 \%$ and $70 \%$ of particles of waste.

Group 3, those made of the C5 condition $100 \%$ of particles of Pinuselliottii) showed the best results for the mechanical properties investigated, with the lowest coming from the C9 condition (100\% of particles of bark). With regard to MOR, the materials of $\mathrm{C} 5$ conditionshown to be $27.11 \%$ and $98.46 \%$ higher when compared with materials manufactured of $\mathrm{C} 1$ conditions( $100 \%$ of particles ofEucalyptus grandis)and C9 respectively.As in the MOR, the MOE of the materials of C5 condition be presented $13.70 \%$ and $66.34 \%$ higher when co mpared to the materials made of the $\mathrm{C} 1$ and $\mathrm{C} 9$ conditions respectively.

\section{Conclusions}

The inclusion of waste particle spruning of Pinuselliottii speciesin materials made from wood particles of Pinuselliottii and Eucalyptusgrandis species conferred significant reductions in both mechanical properties investigated, except for MOE materials manufactured from particles of Eucalyptus(Group1).

The results of bending strength in all experimental conditions investigated were below the limit of $18 \mathrm{MPa}$ stipulated by Brazilian ABNTNBR14810[16] standard, the highest value being obtained from the composition with $100 \%$ of partic les of Pinuselliottii species.

In future work will be necessary to adjust the process parameters used here as the inclusion of other factors such as the treatment of the particles, so that the regulatory 
requirements are met and allow for proposing the use of panels thus produced.

\section{ACKNOWLEDGEMENTS}

To FAPESP (Fundação de Amparo à Pesquisa do Estado de São Paulo), for the scholarship granted to the first author.

\section{REFERENCES}

[1] Uysal, B. Withdrawal strength of various laminated veneer dowels from composite materials. Wood and Fiber Science, Vol. 37, issue 2, pp. 213-219, 2005.

[2] Widsten, P.; Laine, J. E.; Tuominen, S.; Qvintus-Leino, P. Effect of high defibration temperature on the properties of medium-density fiberboard (MDF) made from laccase-treated hardwood fibers. Source: Journal of Adhesion Science and Technology, v 17, n 1, p 67-78. Finland. 2003.

[3] Nemli, G.; Kirci, H.; Temiz, A. Influence of impregnating wood particles with mimosa bark extract on some properties of particleboard. Industrial Crops and Products vol. 20, n. 3, p. 339-344, 2004.

[4] Jun Li, S.; Bernard, R. ; Zhang, S. Y.; Kocaefe, D. Feasibility of using two exotic larch species as raw material for medium density fiber board panel manufacturing. Forest Products Journal, v.56, issue 5, pp. 48-52, 2006.

[5] Akgüla, M.; Çamlibelb, O. Manufacture of medium density fiberboard (MDF) panels from rhododendron (R. ponticum L.) biomass. Building and Environment. Part Special: Building Performance Simulation, Volume 43, Issue 4, pp. 438-443, 2008.

[6] Tibor, A.; Tibor, F.; István1, R.; Gabor, K. MDF/HDF production from plantation wood species. Journal DrvnaIndustrija, v 61, n 3, pp. 183-191, September 2010.

[7] Saffian, H. A.; Harun, J.; Thair, P. M; Abdar, K. Feasibility of Manufacturing a Medium Density Fibreboard Made of 4-Year Old Rubber Tree RRIM 2020 Clone. Key Engineering Materials - Composite Science and Technology, Vol. 471, pp. 839-844, 2011.
[8] Bradi, K. H.; Amim, K.A.M.; Othman, Z.; Manaf, H.A.; Khalid, N. K. Efect of filler-to-matrix blending ratio on the mechanical strength of palm-based. Source: Polymer International 55 (2): p. 190 - 195.

[9] José, F. J.; Beraldo, A. L. Chapas prensadas de partículas de bambu e adesivo poliuretana à base de óleo de mamona. In: Anais do X Encontro Brasileiro em Madeiras e em Estruturas de Madeira; 2006; São Pedro. São Paulo. v. 1, p.1-11, 2006.

[10] Dias, F. M. Aplicação de resina poliuretana à base de mamona na fabricação de painéis de madeira aglomerada. In: LAHR, F. A. R. Produtos derivados da madeira. São Carlos: EESC/USP, p. 37-160, 2008.

[11] Fiorelli, J.; Rocco Lahr, F. A.; Nascimento, M F.; Savastano Jr., H.; Rossignolo, J. A. Painéis de partículas à base de bagaço de cana e resina de mamona - produção e propriedades. ActaScientiarum. Technology, Maringá, v. 33, n. 4, p. 401-406, 2011.

[12] Paes, J. B.; Nunes, S. T; Rocco Lahr, F. A.; Nascimento, M. F.; Lacerda, R. M. A. Qualidade de chapas de partículas de pinus elliottii coladas com resina poliuretana sob diferentes combinações de pressão e temperatura. CiênciaFlorestal, Santa Maria, v. 21, n. 3, p. 551-558, 2011.

[13] Sartori, D. L.; Cravo, J. C. M.; Barrero, N. G.; Fiorelli, J.;Savastano Jr., H. Painel em madeira de reflorestamento e chapas de partículas para instalações rurais. Floresta e Ambiente, 19(2), p. 171-178, 2012.

[14] Associação Brasileira da Indústrias de Painéis de Madeira (ABIPA) - Produtos E Tecnologias. Sobre consumo mundial de aglomerado em 2004/2005, www.abipa.org.br, São Paulo - SP. 2006.

[15] Carlo, E.;Polito, W. L. Desenvolvimento e caracterização de um poliuretano monocomponente baseado em óleo vegetal curado ao ar. Dissertação (Mestrado). Instituto de Química de São Carlos. Universidade de São Paulo; p.282. São Carlos - São Paulo, 2002.

[16] Associação Brasileira de Normas Técnicas - ABNT NBR 14810: Chapas de madeira aglomerada - parte 2: Requisitos; - parte 3: Métodos. Rio de Janeiro, 2006.

[17] Montgomery, D. C. Design and analysis of experiments. John Wiley \& Sons Inc., $6^{\mathrm{a}}$ edition, Arizona, 2005. 